\title{
Intractable Pain Management by Combined Korean Medicine Treatment Including Acupotomy in Lumbar Disc Herniation: A Case Report
}

\author{
Hyeon Kyu Choi, Young Rok Lee, Hyun Ji Cha, Ki Jung Sung,
}

Beom Seok Kim, Min Ju Kim, Ye Ji Lee, Ju Hyun Jeon, Young II Kim

Department of Acupuncture and Moxibustion Medicine, College of Korean Medicine, Daejeon University

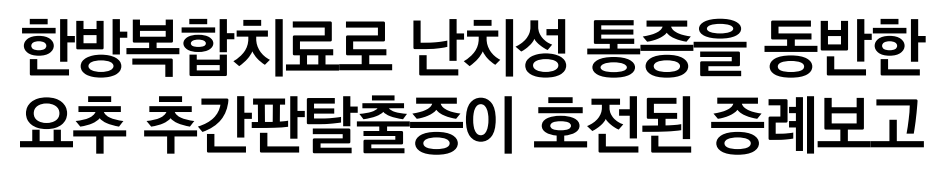

최현규 ${ }^{(1)} \cdot$ 이영록 $^{(1)} \cdot$ 차현지 $^{(1)} \cdot$ 성기정 $^{(1)} \cdot$ 김범석 $^{(1)} \cdot$ 김민주 $^{(1)} \cdot$ 이예지 ${ }^{(1)}$ 전주현 ${ }^{(1)} \cdot$ 김영일 $^{(1)}$

대전대학교 한의과대학 침구의학과

\begin{abstract}
A 57-year-old female diagnosed with L5-S1 lumbar intervertebral disc herniation, suffering from severe pain despite taking tapentadol received combined Korean medicine treatment, including acupotomy, acupuncture, pharmacopuncture, and herbal therapies for 53 days. To assess pain, Numeric Rating Scale (NRS) and lumbar range of motion (ROM) were checked daily from the day of admission. Moreover, the Oswestry Disability Index (ODI) and European Quality of Life-5 Dimensions (EQ-5D) were used to evaluate function and quality of life. After combined Korean medicine treatment, reabsorptioin of intervertebral disc was confirmed by radiological examination; pain reduced from NRS $5 \sim 7$ to NRS 1 2; lumbar ROM in extention increased from $20^{\circ}$ to $30^{\circ}$; and function and quality of life improved. The results suggest the possibility that a combined Korean medical treatment, including acupotomy, can be used as an alternative to opioids for pain management of lumbar vertebral disc herniation.
\end{abstract}

Key words : opioid, lumbar intervertebral disc herniation, acupotomy, combined Korean medicine treatment

\section{Introduction}

Lumbar disc herniation (LDH) is a degenerative disease, in which the nucleus pulposus in the intervertebral disc of the lumbar spine is displaced because of the damage to the annulus fibrosus ${ }^{1)}$. The first radiographic sign is disc space stenosis due to intervertebral disc degeneration, and MRI shows that the disc is displaced out of the vertebral space. Typical clinical features include sudden-onset back pain, radiating pain in the lower extremities, or paresthesia in the lower extremities, but back pain could not appear ${ }^{2}$.

$\mathrm{LDH}$ treatment is divided into surgical and conservative treatment ${ }^{3)}$. For drug treatment, which is one of the conservative treatments, nonsteroidal anti-inflammatory drugs

Received July 28, 2021, Revised August 19, 2021, Accepted August 22, 2021

Corresponding author: Young II Kim

Department of Acupuncture and Moxibustion Medicine, College of Korean Medicine, Daejeon University, 75 Daedeok-daero 176 beon-gil, Seo-gu, Daejeon 35235, Korea

Tel: +82-42-470-9137, Fax: +82-42-470-9008, E-mail: omdkim01@dju.kr

(C) This is an open access article distributed under the terms of the Creative Commons Attribution Non-Commercial License (http://creativecommons.org/licenses/ by-nc/4.0) which permits unrestricted non-commercial use, distribution, and reproduction in any medium, provided the original work is properly cited. 
are effective for chronic low back pain as first-line drugs ${ }^{4}$, and if they are not effective, opioids are used, which are reported to be effective for nociceptive or neuropathic pain ${ }^{5)}$. However, the long-term use of opioids can cause various problems with side effects, including tolerance, withdrawal, addiction, and hyperalgesia ${ }^{6}$. A report revealed that abuse occurs in about $21 \% \sim 29 \%$ of patients taking opioids for chronic pain relief and that $8 \% \sim 12 \%$ of the cases develop into an addiction disorder ${ }^{7)}$.

Lately, in the United States, acupuncture has been recommended as an alternative to acute and chronic pain treatment to avoid opioid abuse ${ }^{8,9)}$. As a conservative treatment for $\mathrm{LDH}$, the effects of acupuncture, acupotomy, pharmacopuncture, and herbal medicine have been widely reported $^{10-12)}$, while the effect of using combined Korean medical treatment in patients with $\mathrm{LDH}$ taking opioids because of failure of pain control using conventional analgesic drugs has not been reported. Thus, to the best of our belief, this is the first case report that presents this case with a patient who was taking opioids; had low back pain, lower limb pain, and standing and walking restrictions due to $\mathrm{LDH}$; and showed significant improvement after acupotomy and combined Korean medicine therapy.

This study was exempt from Korean Medicine Hospital of Daejeon University IRB deliberation (IRB No.: DJDSKH-21E-18-1).

\section{Case}

\section{History taking}

The participant was 57 year old female, whose principal complaints were low back pain, left lower limb pain, and restriction of standing and walking, which occurred for the first time in 2016, with no specific cause. In 2016, the patient first presented with the symptoms and was treated by an orthopedic surgeon with injection. Since 2018, the pain has repeatedly occurred, and the patient received periodic injections and treatment every 8 months at the local hospital until 2021. On February 9, 2021, the pain suddenly worsened. Lumbar spine MRI showed an L5-S1 disc herniation, and afterward, she underwent nerve block twice while receiving inpatient treatment. Tapentadol hydrochloride (HCl)-based opioids were prescribed because of the extreme pain, and the patient was hospitalized at the Korean Medicine Hospital on March 24, 2021 (Table 1).

\section{Physical examination}

The physical examination revealed the following (Right side/Left side):

SLR test $80^{\circ} / 40^{\circ}(+)$

Milgram test 5 seconds

Flexion $50^{\circ}(+)$

Lateral bending $35^{\circ} / 35^{\circ}$

Rotation $45^{\circ} / 45^{\circ}$

\section{MRI findings}

Lumbar spine MRI (2021.02.09): L5-S1 Extrusion (Fig. 1)

\section{Rule out}

The patient complained of the pain not only of low back area but lower limb area as well. And the lower limb pain increased through leg raising motion at supine position. The radiating pain ran through left gluteal region and posterior, lateral lower limb, and reached to left foot region. By the result of physical examination and MRI finding we concluded

Table 1. Case report timeline

\begin{tabular}{|c|c|c|c|c|}
\hline & 2016.05 & 2018.03 & 2021.02 & 2021.03 \\
\hline $\begin{array}{l}\text { Clinical } \\
\text { findings }\end{array}$ & $\begin{array}{c}\text { - Sudden outbreak of the } \\
\text { pain of lower back and } \\
\text { Rt. lower limb region }\end{array}$ & $\begin{array}{l}\text { - Recurrence of the pain } \\
\text { - Progressive clinical } \\
\text { deterioration }\end{array}$ & $\begin{array}{l}- \text { L5-S1 HNP Dx. } \\
\text { (MRI findings) }\end{array}$ & - Hospitalization \\
\hline Treatment & $\begin{array}{l}\text { - Orthopedic surgeon with } \\
\text { injection }\end{array}$ & $\begin{array}{l}\text { - Orthopedic injections and } \\
\text { treatment every } 8 \\
\text { months }\end{array}$ & $\begin{array}{l}\text { - Spinal nerve block } \\
\text { injection and Tapentadol } \\
\text { HCL }\end{array}$ & $\begin{array}{l}\text { - Tapentadol HCL (First } 4 \\
\text { days) and Combined } \\
\text { Korean medicine treatment }\end{array}$ \\
\hline
\end{tabular}




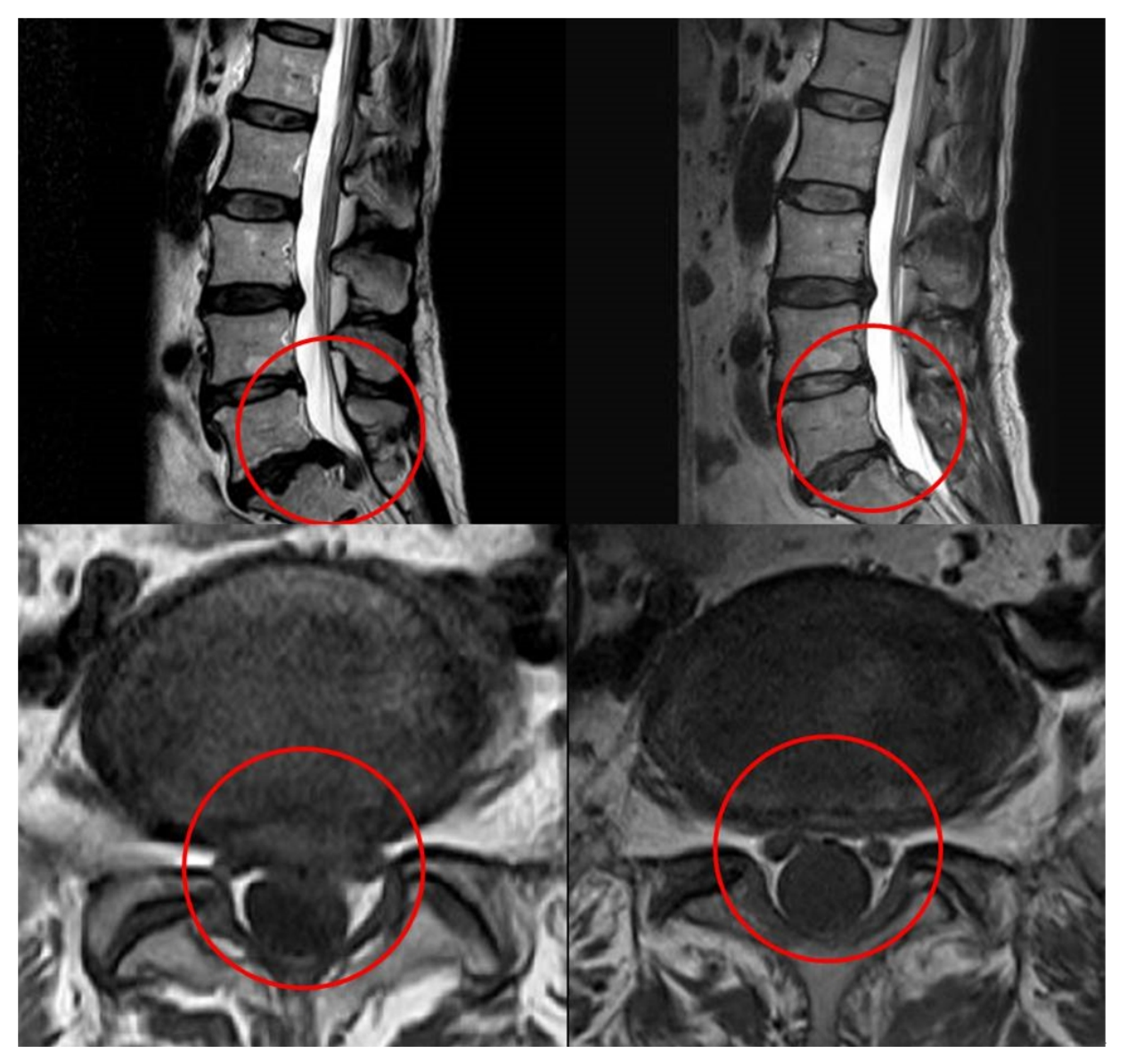

Fig. 1. L-spine MRI (Lt. - 2021.02. 09, Rt. - 2021.06.17, Upper Sagittal view, Lower - Transverse view). the patient's diagnosis as $\mathrm{LDH}$.

\section{Treatment methods}

1) Acupotomy: Acupotomy was performed by an acupuncture specialist with $>5$ years of experience in acupotomy treatment. Before the treatment, the patient was informed about the effects and side effects of acupotomy and provided a consent form. During 53 days of hospitalization, from March 24, 2021, to May 15, 2021, she underwent 5 sessions of acupotomy per week, which is 39 sessions in total. The performer wore disposable surgical gloves and mask, and disinfected the treatment area of the patient with alcohol swabs and povidone stick swabs. Disposable acupotomy needle was used to the acupoints, including BL21, BL22, BL23, BL24, BL25, and BL26 (Fig. 2). During the treatment, needle was slid in and out, and then taken out without retention.

2) Acupuncture: Acupuncture was performed twice a day using disposable sterilized needles (DONGBANG Medical Co.,

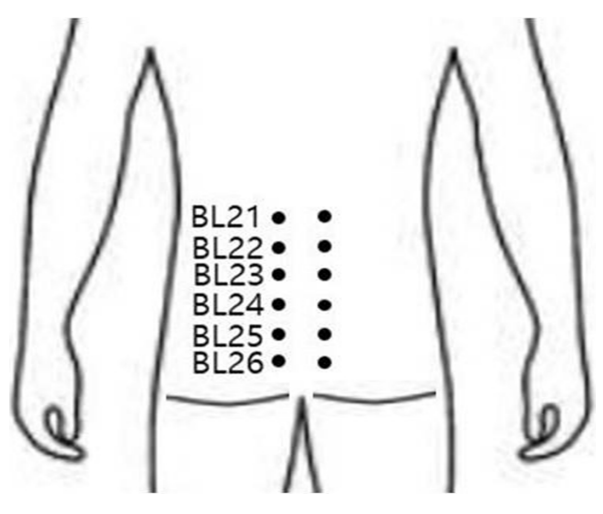

Fig. 2. Acupotomy points.

Ltd., Boryeong, Korea, $0.20 \times 30 \mathrm{~mm}$ ). The needle retention time was 15 minutes per session. The acupoints used were located in the lumbar vertebral area (BL21, BL22, BL23, BL24, BL25, and BL26) and the distal area (SI3, BL62, TE3, GB39, GB34, BL40, ST36, and BL60) ${ }^{10)}$.

3) Pharmacopuncture: Pharmacopuncture was performed daily. Bee venom pharmacopuncture (BVP, Korean Pharma- 
copuncture Research Institute) was performed five times a week and Soyeom pharmacopuncture (SYP) twice a week. BVP is formulated with purified $99.9 \%$ pure melittin 0.10 $\mathrm{mg} / \mathrm{ml}$. The patient was informed about precautions and side effects. Afterward, we obtained informed consent and confirmed no adverse reactions through a skin reaction test. The formula was subcutaneously injected into the acupoints on both sides of the lumbar area (BL22, BL23, BL24, BL25, and BL26), $0.1 \mathrm{~mL}$ per point, $1 \mathrm{~mL}$ in total, using a $13-\mathrm{mm} 30$ G needle $e^{10)}$.

4) Herbal medicine: For the first 6 days of hospitalization, the patient took Modified-Hwallaktang1, and for the next 28 days, she took Modified-Hwallaktang2 with the modified drug composition. On the 34th day of admission, ModifiedMangeumtang was prescribed. She took the medicine three times a day, 30 minutes after meals. Table 2 presents the composition and daily dose of the above prescription.

\section{Clinical outcome}

During hospitalization, lumbar ROM and Numerical Rating
Scale (NRS) ${ }^{13)}$ were evaluated every day. Additionally, on the day of admission, after 14,28 , and 42 days from the day of admission, and on the discharge day, the patient completed the Oswestry Disability Index (ODI) ${ }^{14)}$ and the 5-level European Quality of Life-5 Dimensions (EQ-5D) questionnaire ${ }^{15)}$ to be conducted into evaluation and comparison. The Korean version of the ODI questionnaire, whose validity had been verified, was used, and the EQ-5D-5L was also calculated by applying quality weights to the status of the Korean standard population.

\section{Clinical course}

After the treatment, a significant improvement was observed in radiological examination, NRS, lumbar ROM, ODI, and EQ-5D scores. Table 3 shows the enhancement of lumbar ROM, ODI, and EQ-5D scores, and Fig. 3 shows the reduction of NRS scores in the lower back area and left lower limb.

The patient was taking opioids twice a day due to the severe pain from before the first day to the fourth day of hospitalization, and in the morning of the fifth day, the pain

Table 2. Composition and daily dose of the herbal medicine

\begin{tabular}{|c|c|c|c|c|c|}
\hline \multicolumn{2}{|l|}{$\begin{array}{c}\text { Modified-Hwallaktang1 } \\
(2021.03 .24 \sim 2021.03 .30)\end{array}$} & \multicolumn{2}{|l|}{$\begin{array}{c}\text { Modified-Hwallaktang2 } \\
(2021.03 .30 \sim 2021.04 .26)\end{array}$} & \multicolumn{2}{|l|}{$\begin{array}{l}\text { Modified-Mangeumtang } \\
(2021.04 .27 \sim 2021.05 .15)\end{array}$} \\
\hline Chaenomelis Fructus & $32(\mathrm{~g})$ & Chelidonii Herba & $18(\mathrm{~g})$ & Rehmanniae Radix Preparata & $24(\mathrm{~g})$ \\
\hline Chelidonii Herba & 16 & Achyranthis Bidentatae Radix & 18 & Dipsaci Radix & 12 \\
\hline Corydalis Tuber & 16 & Chaenomelis Fructus & 18 & Poria Sclerotium & 12 \\
\hline Osterici seu Notopterygii Radix et Rhizoma & 16 & Acanthopanacis Cortex & 16 & Achyranthis Radix & 12 \\
\hline Clematidis Radix & 12 & Corydalis Tuber & 16 & Angelicae Gigantis Radix & 12 \\
\hline Araliae Continentalis Radix & 12 & Zingiberis Rhizoma Crudus & 12 & Ginseng Radix & 12 \\
\hline Angelicae Gigantis Radix & 12 & Jujubae Fructus & 12 & Eucommiae Cortex & 8 \\
\hline Rehmanniae Radix & 12 & Atractylodis Rhizoma & 6 & Saposhnikoviae Radix & 8 \\
\hline Paeoniae Radix & 12 & Angelicae Gigantis Radix & 6 & Cinnamomi Ramulus & 8 \\
\hline Atractylodis Rhizoma & 12 & Rehmanniae Radix & 6 & Cnidii Rhizoma & 8 \\
\hline Citri Unshius Pericarpium & 8 & Paeoniae Radix & 6 & Araliae Continentalis Radix & 8 \\
\hline Olibanum & 8 & Clematidis Radix & 6 & Forsythiae Fructus & 8 \\
\hline Myrrha & 8 & Araliae Continentalis Radix & 6 & Glycyrrhizae Radix et Rhizoma & 8 \\
\hline Carthami Flos & 6 & Citri Unshius Pericarpium & 6 & Asiasari Radix et Rhizoma & 4 \\
\hline Amomi Fructus & 6 & Olibanum & 6 & Scorpio & 4 \\
\hline Glycyrrhizae Radix et Rhizoma & 4 & Myrrha & 6 & & \\
\hline Scolopendra & 4 & Cinnamomi Cortex & 6 & & \\
\hline \multirow[t]{6}{*}{ Eucommiae Cortex } & 4 & Zingiberis Rhizoma & 6 & & \\
\hline & & Glycyrrhizae Radix & 4 & & \\
\hline & & Aconiti Lateralis Radix Preparata & 4 & & \\
\hline & & Aconiti Kusnezoffii Tuber & 4 & & \\
\hline & & Carthami Flos & 4 & & \\
\hline & & Amomi Fructus & 4 & & \\
\hline
\end{tabular}


Table 3. Lumbar ROM and ODI and EQ-5D scores before and after treatment

\begin{tabular}{|c|c|c|c|c|c|}
\hline & $\begin{array}{l}\text { Admission } \\
(2021.03 .24)\end{array}$ & After 14 days & After 28 days & After 42 days & $\begin{array}{c}\text { Discharge } \\
(2021.05 .15)\end{array}$ \\
\hline \multicolumn{6}{|l|}{ ROM } \\
\hline Flexion & $50^{\circ}$ & $50^{\circ}$ & $50^{\circ}$ & $50^{\circ}$ & $50^{\circ}$ \\
\hline Extension & $20^{\circ}$ & $20^{\circ}$ & $30^{\circ}$ & $30^{\circ}$ & $30^{\circ}$ \\
\hline Lateral bending & $35^{\circ} / 35^{\circ}$ & $35^{\circ} / 35^{\circ}$ & $35^{\circ} / 35^{\circ}$ & $35^{\circ} / 35^{\circ}$ & $35^{\circ} / 35^{\circ}$ \\
\hline Rotation & $45^{\circ} / 45^{\circ}$ & $45^{\circ} / 45^{\circ}$ & $45^{\circ} / 45^{\circ}$ & $45^{\circ} / 45^{\circ}$ & $45^{\circ} / 45^{\circ}$ \\
\hline ODI & 39 & 21 & 18 & 12 & 9 \\
\hline EQ-5D (subscore) & $0.206(4-4-4-5-4)$ & $0.604(3-2-3-3-2)$ & $0.593(3-3-3-3-3)$ & $0.613(2-2-3-3-2)$ & $0.663(2-2-2-2-2)$ \\
\hline
\end{tabular}

ROM : Range of motion, ODI : Oswestry Disability Index, EQ-5D : European Quality of Life-5 Dimensions.

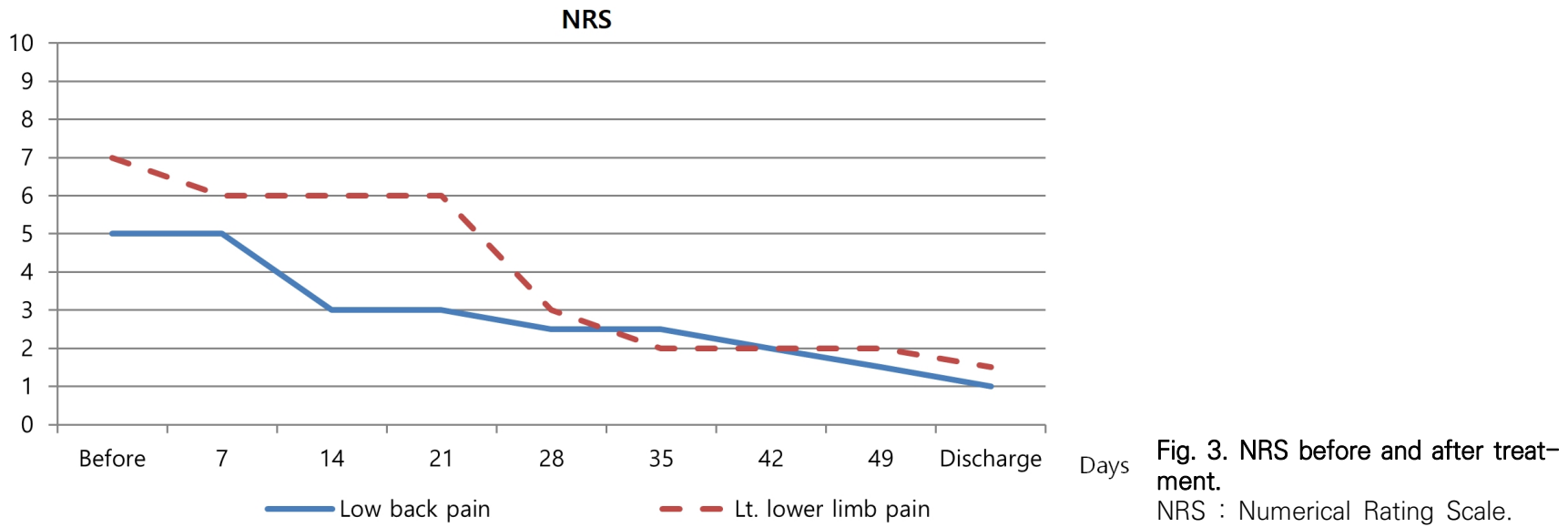

Table 4. Medication before and after treatment

\begin{tabular}{lccccc}
\hline & $0 \sim 4$ days & $5 \sim 14$ days & $15 \sim 29$ days & $30 \sim 43$ days & After 44 days \\
\hline Tapentadol HCl $58.24 \mathrm{mg}$ & $(1-0-1)$ & - & - & - & - \\
Acetaminophen $325 \mathrm{mg}$ & & $(1-1-1)$ & $(1-0-1)$ & Intermittent & - \\
Tramadol HCl $37.5 \mathrm{mg}$ & & $(1-1-1)$ & $(1-0-1)$ & Intermittent & - \\
Eperisone $\mathrm{HCl} 50 \mathrm{mg}$ & & & \\
\hline
\end{tabular}

Prn : Pro re nata, Bid : Bis in die.

improved, and the patient voluntarily tried not taking opioids. Not as much pain as before the fifth day but residual pain was still remained, so from the 6th to the 14th day of hospitalization, an analgesic containing acetaminophen and tramadol and a muscle relaxant containing Eperisone $\mathrm{HCl}$ were prescribed, and she took them three times a day. From the 15th day, the number of doses was reduced to twice a day, and from the 30th day, the dose was taken $1 \sim 2$ times a day only when the pain was severe. On the 44th day, the analgesic was completely stopped (Table 4).

\section{Discussion}

Acupotomy, acupuncture, pharmacopuncture, and herbal medicine treatment were administered for 53 days, from March 24, 2021, to May 15, 2021, to a patient with LDH, who was taking opioids for severe pain. NRS and ROM were evaluated to assess the lumbar pain and function of the patient, and daily living performance was measured by ODI and EQ-5D, and an improvement was observed. The patient had to use a walker to walk, complaining of restriction of standing and walking by herself at the time of admission, but 
she could walk on her own and did not need to use it by the time of discharge. And through MRI examination, we confirmed the improvement in radiology as well. Furthermore, the patient stopped taking opioids, due to the reduce of pain, only after 4 days of treatments.

Disc herniation is a disease in which the nucleus pulposus prolapses and compresses the dura mater or nerve root, causing neurological symptoms. The conservative Korean medicine treatment for LDH includes acupotomy, acupuncture, pharmacopuncture, and herbal medicine ${ }^{10)}$. In our case, a complex treatment was performed for the quick recovery of the patient.

Acupotomy is a new type of acupuncture treatment that removes pain and restores the original dynamic state by exfoliating, incision, or cutting of soft tissue adhesions, to reduce the pressure inside the tissue and release the induration of the deep muscles of the lumbar vertebrae. It improves the surrounding blood circulation disorder through microtrauma and regenerates the lesion tissue into normal tissue by causing an inflammatory reaction ${ }^{16}$. In our case, this treatment mechanism of acupotomy was considered to be involved in pain control.

Pharmacopuncture is another new acupuncture method that combines acupuncture and drug therapy in the form of injecting pharmacopuncture solutions into acupoints using a syringe ${ }^{10)}$. Furthermore, various types are used depending on the indication; for our case, we used $\mathrm{BVP}^{17)}$ and SYP $\mathrm{P}^{13)}$, which have been reported to be effective for patients with $\mathrm{LDH}$.

Herbal medicines were prescribed to relieve pain from the 1 st day to the 33rd day of admission and improve general fatigue and restore systemic functions from the 34th day until discharge ${ }^{18)}$. In our case, since the herbal medicine was changed according to the progress of the patient, more studies are needed to confirm the single effect of herbal medicine on $\mathrm{LDH}$.

The abuse of opioids used for chronic pain management is proliferating worldwide, and it was reported that 3 million US citizens and 16 million people worldwide experience opioid use disorders ${ }^{19)}$. Many of those were due to opioid overdose, and $35.8 \%$ of the US opioid-related drug abuse deaths in 2017 were patients prescribed them for pain management ${ }^{20}$.

This case suggests the possibility that a combined Korean medical treatment, including acupotomy, can be used as an alternative to opioids for $\mathrm{LDH}$ accompanied by extreme pain. Nonetheless, this study has a limitation in that this is a single case study, and determining which factors contributed to what extent is difficult since multiple treatments were performed. Thus, large-scale clinical studies on more patients are needed in the future to prove the effectiveness of using the Korean medicine treatment as an alternative to opioids.

\section{Acknowledgement}

None.

\section{Funding}

None.

\section{Data availability}

The authors can provide upon reasonable request.

\section{Conflicts of interest}

The authors have declared that no conflicts of interest exists.

\section{References}

1. Ludwig O. A System of Orthopaedic Medicine. 3rd ed. Seoul : Hanmi Medicine Publish Company. 2017 ; 455-64.

2. Kim JH. Orthopedics for Primary Care Physicians Diagnosis and Treatment. 2nd ed. Seoul : Daehan Medicine Publish Company. 
$2016 ; 431-3$.

3. Lee GM, Lee GC, Hwang YJ. Collaborative study of oriental-western medicine on HIVD. J Acupunct Res. 2000 ; 17(2) : 1-10.

4. Wong JJ, Côté P, Ameis A, Varatharajan S, Varatharajan T, Shearer $\mathrm{HM}$, et al. Are non-steroidal anti-inflammatory drugs effective for the management of neck pain and associated disorders, whiplash-associated disorders, or non-specific low back pain? A systematic review of systematic reviews by the Ontario Protocol for Traffic Injury Management (OPTIMa) collaboration. Eur Spine J. 2016; 25(1) : 34-61. https://doi.org/10.1007/s00586-015-3891-4

5. Yoon DM. Analgesic therapy according to disease specific pathophysiology. J Korean Med Assoc. 2011 ; 54(7) : 739-46. https://doi.org/10.5124/jkma.2011.54.7.739

6. Manchikanti L, Ailinani H, Koyyalagunta D, Datta S, Singh V, Eriator I, et al. A systematic review of randomized trials of long-term opioid management for chronic non-cancer pain. Pain Physician. 2011 ; 14(2) : 91-121. https://doi.org/10.36076/ppj.2011/14/91

7. Vowles KE, McEntee ML, Julnes PS, Frohe T, Ney JP, Goes DN. Rates of opioid misuse, abuse, and addiction in chronic pain: a systematic review and data synthesis. Pain. $2015 ; 156(4)$ : 569-76. https://doi.org/10.1097/01.j.pain.0000460357.01998.f1

8. Kim JC, Hyun EH, Kim DS. Review of US Health Policy on Acupuncture Application for Opioid Abuse Crisis. J Korean Med. 2020 ; 41(2) : 137-49. https://doi.org/10.13048/jkm.20020

9. Tedesco D, Gori D, Desai KR, Asch S, Carroll IR, Curtin C, et al. Drug-Free Interventions to Reduce Pain or Opioid Consumption After Total Knee Arthroplasty: A Systematic Review and Metaanalysis. JAMA Surg. 2017 ; 152(10) : e172872. https://doi.org/10. 1001/jamasurg.2017.2872

10. Korean Acupuncture \& Moxibustion Society Textbook Compilation Committee. Acupuncture Medicine. 4th ed. Seoul : Hanmi Medicine Publish Company. 2016 ; 173-80, 204-28, 495-6, 510-2.

11. Jang EH, Kim SC, Im NR, Na WM, Im SI, Shin JB, et al. Case Study of Oriental Medicine Treatment with Acupotomy Therapy of the Herniated Lumbar Intervertebral Disc Patient. J Acupunct Res.
$2008 ; 25(4): 171-81$.

12. Lee GM, Kim DH, Kim HW, Yum SC, Kim HS, Kim DE, et al. The study on the effect of acupotomy in lumbar HIVD. J Acupunct Res. 2008 ; 25(4) : 183-90.

13. Song HG, Choi JY, Kang JH, Lee H. The Effect of the Acupuncture Therapy in Combination with Soyeom Pharmacopuncture Therapy on the Improvement of the Symptoms of the Patients with Herniated Intervertebral Disk of L-spine in His Initial Stage of Hospitalization. J Pharmacopuncture. 2009 ; 12(4) : 111-8.

14. Jeon CH, Kim DJ, Kim SK, Kim DJ, Lee HM, Park HJ. Validation in the Cross Cultural Adaptation of the Korean Version of the Oswestry Disability Index. J Korean Med Sci. 2006 ; 21(6) : 1092-7. https://doi.org/10.3346/jkms.2006.21.6.1092

15. Kim SH, Ahn JH, Ock MS, Shin SJ, Park JY, Luo N, et al. The EQ-5D-5L Valuation Study in Korea. Qual Life Res. 2016 ; 25(7) : 1845-52. https://doi.org/10.1007/s11136-015-1205-2

16. The Institute of Korean Acupotomy Medicine. Acupotomy. Seoul : Jeongdam. 2003 ; 81-82, 87, 113.

17. Park OJ, Kim SG, Lee JJ, Lee SM, Kim SJ, Cho NG. The Effect of Shinbaro and Bee Venom Pharmacopuncture in Treating Lumbar Disc Herniations. J Acupuncture. 2013 ; 30(5) : 41-50. https://doi.org/10.13045/acupunct.2013044

18. Kim KW, Kim TJ, Park HB, Yoo DH, Kim H, Lee SG, et al. Intensive Korean Medicine Treatments for Low Back Pain and Decreased Living Function due to Herniation Intervertebral Discs in the Lumbar Spine: A Case Study. J Int Korean Med. 2020; 41(2) : 283-92. https://doi.org/10.22246/jikm.2020.41.2.283

19. Azadfard M, Huecker MR, Leaming JM. Opioid AddictionStatPearls. 2020. [cited 2021 May 21]. Available from: https://www.ncbi. nlm.nih.gov/books/NBK448203/

20. Hedegaard H, Miniño AM, Warner M. Drug Overdose Deaths in the United States, 1999-2017. NCHS Data Brief. 2018 ; (329) : 18. 